\title{
O corpo feminino na obra de Adriana Varejão: transgressão e ruptura
}

Nincia Cecilia Ribas Borges Teixeira*

\section{Resumo}

O presente artigo analisa a representação do corpo feminino na obra da artista plástica Adriana Varejão, reconhecendo a arte como veículo de significação e comunicação visual. $\mathrm{O}$ corpo é uma forma de identificação do feminino e do masculino, mas é especialmente tido como um estigma da representação do poder masculino. Em toda a história fica evidente a divisão entre o público, no que se refere aos papéis masculinos, e o privado, quanto aos papéis femininos. E para $o$ âmbito da representação artística que voltaremos nosso olhar, ou seja, para a análise de como se dá o olhar estético do autor na captação da concepção dominante na poética do corpo feminino. Adotamos o método hermenêutico de interpretação; a hermenêutica moderna engloba não somente textos escritos, mas também tudo que há no processo interpretativo. Isso inclui formas verbais e não verbais de comunicação, assim como aspectos que afetam a comunicação. Interpretar significa atribuir o conteúdo, sentido e alcance de um texto normativo, visando à sua aplicação a um caso concreto.

Palavras-chave: Adriana Varejão. Arte. Corpo. Mulher.

\section{Introdução}

[...] o corpo é então compreendido como uma exteriorização do interior psíquico do sujeito, fazendo, dessa maneira, a fronteira entre $o$ individual e $o$ social (NOVAES, 2006, p. 58).

As lutas de representações, conforme Roger Chartier (1991), apontam para conflitos e mecanismos de poder utilizados para estabelecer grupos e suas visões de mundo sobre outros:

As lutas de representações têm tanta importância como as lutas econômicas para compreender os mecanismos pelos quais um grupo impõe, ou tenta impor, a sua concepção do mundo social, os valores que são os seus, o seu domínio (CHARTIER, 1991, p. 17).

\footnotetext{
Doutora em Letras com período pós-doutoral em Ciência da Literatura. Professora associada do Programa de Pós-graduação do Departamento de Letras, da Universidade Estadual do Centro-Oeste (UNICENTRO). Coordenadora do Laboratório de Estudos Culturais, Identidades e Representações (LABECIR/UNICENTRO). E-mail: ninciaborgesteixeira@yahoo.com.br
}

Data de submissão: 04/07/2017 - Data de aceite: ago. 2017 http://dx.doi.org/10.5335/rdes.v13i2.7177 
A construção do masculino e do feminino determinou lugares, ações e papéis que cabiam a cada sexo. $O$ estudo de gênero não tenta compreender modelos e identidades fixados socialmente na essência do feminino ou do masculino, de forma naturalizada e a-histórica, mas as relações entre homens e mulheres de um dado momento e de um dado local. As abordagens de gênero

[...] procuram, assim recobrar o pulsar na história, recuperar sua ambiguidade e a pluralidade de possíveis vivências e interpretações, desfiar a teia de relações cotidianas e suas diferentes dimensões de experiência, fugindo dos dualismos e polaridades e questionando as dicotomias (MATOS, 1997, p. 80).

A atuação da mulher, nos variados contextos sociais, foi construída por lutas, palavras e também silêncio. Silêncio que gerou sentidos e mudou o curso da história. Nesse universo em transformação, inúmeros foram os discursos que socialmente se elucidaram a respeito da questão de gênero, e diferentes foram os sentidos a eles atribuídos. A sociedade patriarcal traduz bem esse silêncio que denuncia as formas de opressão a que foram submetidas as mulheres. Ao longo da história, mulheres de variadas culturas assumiram papéis que estiveram numa posição quase sempre inferior às funções assumidas por homens. Em algumas sociedades, as mulheres foram, e ainda são, vítimas de abuso de poder. $\mathrm{O}$ único lugar em que a mulher pôde ter a falsa sensação de estar no comando foi dentro de sua própria casa.
A emergência do movimento feminista, no final da década de 1960, produziu novos modos de representação do feminino no campo da arte, desencadeando, assim, a necessidade de questionamentos sobre a formação da identidade de gêneros e suas respectivas "funções" dentro da sociedade ocidental. No âmbito artístico, o gênero loca-se no processo de questionamento da grande presença de nomes masculinos na História da Arte, no mercado de arte, e na inserção midiática das recentes temáticas contemporâneas, ou seja, as poéticas intimistas, sexuais e subjetivas.

A questão do gênero e, posteriormente, o feminismo criaram, assim, pontes de diálogo com o universo feminino dentro do universo artístico, até então estritamente masculino. Durante grande parte da história da arte ocidental, as mulheres figuravam como musas ou como assistentes e não como artistas criadoras. Deixando de serem espectadoras, as mulheres tomaram a "liberdade" de serem criadoras e de determinarem suas imagens artísticas, de elegerem suas poéticas. $\mathrm{O}$ movimento feminista na arte vem então para desconstruir a premissa de mulher objeto de desejo. De musas inspiradoras para o olhar do artista, a mulher passa a ser o olho e a mão que criam. Ao tentar romper com essa perspectiva histórica, muitas escritoras, jornalistas, artistas e compositoras explicitaram em seus trabalhos a insatisfação com tal condição. A artista 
plástica Adriana Varejão é uma dessas mulheres.

Segundo Trizoli (2008), a solidificação do movimento feminista no final da década de 1960 não apenas produziu reações e contrarreações no seio da sociedade patriarcal, no que diz respeito ao comportamento sexual ou ao mundo do trabalho, mas também afetou principalmente a distribuição de papéis sociais em diversos âmbitos das estruturas normalizantes vigentes. A arte não saiu ilesa desse processo. Os parâmetros da História da Arte e os modos de representação do feminino e suas adjacências receberam tais conteúdos, desencadeando assim a necessidade de questionamento dos valores pertinentes à área e colocando sob forte análise pós-estruturalista a epistemologia acadêmica. As questões de gênero passaram então a fazer parte, ora de modo direto, ora indireto, dos modos de avaliação e de criação de um objeto artístico, já que críticos, historiadores, marchands, compradores e artistas tiveram sua rotina e suas concepções de mundo alteradas pelas recentes premissas da formação da identidade sexual e suas respectivas "funções" dentro da sociedade ocidental.

O corpo é uma forma de identificação do feminino e do masculino, mas é especialmente tido como um estigma da representação do poder masculino. Em toda a história fica evidente a divisão entre o público, no que se refere aos papéis masculinos, e o privado, quanto aos papéis femininos. É para o âmbito da representação artística que voltare- mos nosso olhar, ou seja, para a análise de como se dá o olhar estético do autor na captação da concepção dominante na poética do corpo feminino. A teoria feminista coloca a questão do corpo no centro da ação política e da produção teórica. São várias as posições feministas, que resultam, muitas vezes, em visões diferentes e até mesmo opostas. Simone de Beauvoir percebe que o corpo das mulheres é importante, mas não é fundamental:

\begin{abstract}
A sujeição da mulher à espécie, os limites de suas capacidades individuais são fatos de extrema importância; o corpo da mulher é um dos elementos essenciais da situação que ela ocupa neste mundo. Mas não é ele tampouco que basta para a definir. Ele só tem realidade vivida enquanto assumido pela consciência através das ações e no seio de uma sociedade; a biologia não basta para fornecer uma resposta à pergunta que nos preocupa: por que a mulher é o Outro? Trata-se de saber como a natureza foi nela revista através da história; trata-se de saber o que a humanidade fez da fêmea humana (BEAUVOIR 1970 apud XAVIER, 2007, p. 112).
\end{abstract}

Hélène Cixous, Gayatri Spivak e Judith Butler, entre outras, concebem o corpo como um objeto cultural, utilizado de formas específicas em culturas diferentes. Para elas, o corpo deve ser visto como o lugar de contestação, de lutas econômicas, políticas, sexuais e intelectuais. Observa-se, pois, que os corpos devem ser vistos mais em sua concretude histórica do que na sua concretude simplesmente biológica. Existem apenas tipos específicos de corpos, marcados pelo sexo, pela raça, pela classe social e, portanto, com 
fisionomias particulares. Essa multiplicidade deve solapar a dominação de modelos, levando em conta outros tipos de corpos e subjetividades. Elisabeth Grosz (2000) sugere, como abordagem teórica feminista dos conceitos sobre o corpo, a recusa do dualismo mente/ corpo, apontando para o entendimento de uma subjetividade corporificada, de uma corporalidade psíquica. E completa, dizendo: "O corpo deve ser visto como um lugar de inscrições, produções ou constituições sociais, políticas, culturais e geográficas" (2000, p. 54).

A "subjetividade corporificada" ou a "corporalidade psíquica" da mulher, representada nos textos de autoria feminina, inscreve-se no contexto social de forma variada, o que nos permite o estabelecimento de uma tipologia, agrupando as personagens femininas em torno dos vários tipos de representação. Para Grosz (2000), o pensamento misógino define uma autojustificativa conveniente para a posição social secundária das mulheres ao contê-las no interior de corpos que são representados, até construídos, como frágeis, imperfeitos, desregrados, não confiáveis, sujeitos a várias intrusões que estão fora do controle consciente.

A sexualidade feminina e os poderes de reprodução das mulheres são as características culturais definidoras das mulheres e, ao mesmo tempo, essas mesmas funções tornam a mulher vulnerável, necessitando de proteção ou de tratamento especial, conforme foi variadamente prescrito pelo patriarcado.
Assim, a noção que emerge é a de que os corpos das mulheres são presumidamente incapazes das realizações masculinas, sendo mais fracos, mais expostos a irregularidades hormonais, intrusões e imprevistos. Dessa forma, observa-se como ocorrem a dominação masculina e a construção social e histórica dos corpos. Para Xavier (2007), é na interação com alguém ou alguma coisa que os corpos devem ser vistos. O sexo feminino carrega o peso de ser um corpo subalterno devido a questões culturais produzidas através dos tempos. Segundo Bourdieu (1999), a diferença biológica entre o corpo masculino e o corpo feminino é a responsável pelas diferenças de gênero socialmente construídas. Essas diferenças estão na ordem das coisas de forma objetivada, na casa, por exemplo, em todo o mundo social, e de forma já incorporada nos corpos e na cultura das pessoas.

Nas palavras do Bourdieu:

A constituição da sexualidade [...] nos fez perder o senso da cosmologia sexualizada, que se enraíza em uma tipologia sexual do corpo socializado, de seus movimentos e seus deslocamentos, imediatamente revestidos de significação social - o movimento para o alto sendo, por exemplo, associado ao masculino, como a ereção, ou a posição superior no ato sexual (1999, p. 15-16).

Conforme o autor, as situações segundo as oposições masculino/feminino, superior/inferior, alto/baixo, direita/ esquerda, em cima/embaixo, etc. são consideradas para muitos análogas aos movimentos do corpo. Também está socialmente construída a ideia de potência sexual do homem, ou o que se espera "de 
um homem que seja realmente um homem" (BOURDIEU, 1998, p. 20). Assim, explica-se porque a sociedade é regulada pela ordem patriarcal e ditatorial e porque o corpo feminino é, na maioria das vezes, representado de forma subalterna.

Perrot (2007) assegura que de Aristóteles a Freud, o sexo feminino era visto como um defeito, como se fosse uma fraqueza da natureza, marcado para a possessão, tanto por sua anatomia quanto por sua biologia. Mais tarde, os homens passam a cobiçar a virgindade das moças. Passa-se a discutir o prazer sexual feminino e, até hoje, discute-se o valor da maternidade. Entretanto, o universo da sexualidade feminina ainda é algo a ser explorado. "O sexo das mulheres é um poço sem fundo, onde o homem se esgota, perde suas forças e sua vida beira a impotência" (PERROT, 2007, p. 65). O que é condenado, especialmente pelas feministas, é a associação da oposição macho/fêmea com a oposição mente/corpo, responsável pela discriminação das mulheres. Simone de Beauvoir (1970) afirma que o conceito do corpo feminino é um obstáculo a ser superado para que se chegue à igualdade.

$\mathrm{Na}$ pós-modernidade, diversificam-se as maneiras de se olhar o corpo, suscitando nas obras de arte sucessivas metáforas corporais, que envolvem, além do aspecto biológico, o estético-cultural, o histórico-social. Assim, o corpo, muito mais que um objeto, um instrumento ou um produto de consumo, torna-se um sistema, graças à relação entre corpo biológico e corpo cultural. Segundo Katz e Greiner, "O corpo anatômico e o corpo vivo atuando no mundo tornaram-se inseparáveis" (1998, p. 42).

Num percurso por algumas dessas expressões do corpo feito poesia, segue-se uma breve leitura de elementos de uma poética cultural corporal em alguns autores que, mineiros de nascimento, fizeram do verso sua linguagem universal, sua leitura pessoal da condição humana. Nesses poetas, a arte da palavra dialoga e funde-se com outras artes, como teatro, música, desenho e pintura, em um constante jogo entre real e imaginário, fazendo-se registro poético sinestésico da vida que emerge do corpo humano e do corpo social.

Toda imagem é tomada de poder ou significações que, em algumas vezes, transcendem o material e atuam no subjetivo. De acordo com Joly (1996), a imagem é a reprodução de uma sensação, conceito ou objeto. Na concepção de Aumont (1993), a imagem é feita para representar algo coletivo ou individual. Por registrar intencionalmente algo coletivo ou individual ela é "um meio de expressão e comunicação" (JOLY, 1996, p. 135).

O corpo feminino e suas facetas podem colaborar para o empoderamento de mulheres e para a conquista de direitos e reconhecimento. O corpo deve ser compreendido não como a prisão do ser, mas como sua libertação, não como castração, mas como um veículo que possibilita mover-se pela estrada da vida. Nesse sentido, a hipervisibilização do corpo não 
é interpretada negativamente, mas como catalisadora do empoderamento feminino. O corpo humano aparece em diferentes obras da artista Adriana Varejão, e as obras fazem alusão a diferentes corpos: ao corpo barroco, ligado à tradição barroca, cuja ênfase é para a matéria e para o corpo; ao corpo colonizado brasileiro; ou ao corpo da pintura. Um corpo-imagem que a artista representa como comida, cortada e morta. Nesta pesquisa, a imagem do corpo na obra de Varejão tem a capacidade de comunicar, ou seja, o corpo imagético indica/conta algo não escrito, por meio de formas, ícones e símbolos figurativos. Aceitando a imagem como forma simbólica (THOMPSON, 1995), interpretamos/reinterpretamos a obra Figura de Convite III.

Assim, interpretamos as imagens na obra de Adriana Varejão à luz da Hermenêutica de Profundidade, de John B. Thompson (1995), justificando a escolha do método porque, tal como o autor, percebemos as imagens como formas simbólicas, ou seja,

[...] construções significativas que exigem uma interpretação; elas são ações, falas, textos que, por serem construções significativas podem ser compreendidas (THOMPSON, 1995, p. 357).

Da mesma forma, a Hermenêutica de Profundidade pode auxiliar nossa reinterpretação das imagens, porque traz à luz um conjunto de condições sob as quais os sujeitos contemporâneos percebem estas imagens, apontando-nos pistas para a compreensão da interpretação que esses sujeitos têm delas. Além disso, o método hermenêutico de análise engloba não somente textos escritos, mas também tudo que há no processo interpretativo. Isso inclui formas verbais e não verbais de comunicação, assim como aspectos que afetam a comunicação. Interpretar significa atribuir o conteúdo, sentido e alcance de um texto normativo, visando à sua aplicação a um caso concreto. Não se concebe, dessa forma, a ideia de que o intérprete exerça um papel de mera descrição do significado; o processo de interpretação implica, pois, compreensão, fundamentação e reconstrução (visão triádica da interpretação) de significados.

\section{Adriana Varejão: transgressão e ruptura}

Se meu campo fosse a literatura, es-
creveria romances históricos. Sou uma
artista contemporânea com preocu-
pações atuais. As figuras da História
que utilizo, apesar de recorrentes, são
moldadas para um tempo presente.
Faço uso da paródia, de arremedos (VAREJÃO, 2005b).

As relações mais acentuadas entre 0 movimento feminista e a arte ocorrem em meados do final dos anos 1960, nos Estados Unidos. De acordo com Trizoli (2008), a arte feminista da década de 1960 é marcada pelo teor de denúncia, revolta e inconformismo que prevaleciam em diversos campos intelectuais, criando assim um canal de abertura para a arte politizada e intelectualizada (a conceptual art) da década seguinte. No início da década de 
1970, período de desenvolvimento da arte conceitual e da desmaterialização da arte, surge o primeiro programa acadêmico de arte feminista, o Feminist Art Program, de Judy Chicago e Miriam Schapiro, na Califórnia, que permitiu a inserção e o desenvolvimento do pensamento feminista dentro da acadêmica americana e oficializou o pensamento de teóricas feministas com a produção artística. Na década de 1980 , as artistas mulheres trabalharam com uma forte crítica ao essencialismo na arte e apareceram também os primeiros sinais de aversões quanto a aspectos racistas, conservadores e eurocentristas dentro do Feminist Art.

A história da arte e o mercado de arte estão imbricados de valores morais da sociedade a qual pertencem, refletem ânsias, preconceitos e valores vigentes. A arte feminista é pluralista, portanto deve-se afirmar que existem artes feministas, em que a valorização das diferenças na subjetividade de seus artífices e espectadores é elemento primordial para sua subsistência. Existem artistas que trabalham com essas temáticas, mas não se definem sob influência feminista, ou mesmo conhecem seu desencadeamento. No entanto, nos trabalhos daqueles familiarizados com o pensamento teórico de Judith Butler, Simone de Beauvoir e Joan Scott, bem como na larga aplicação de elementos, materiais e práticas presentes em composições e discursos, fica difícil não perceber as conexões inconscientemente realizadas pela influência do pensamento feminista. Marcia Tucker afirma a respeito disso em seu livro Bad Girls:

[...] algumas mulheres que recusam o termo categoricamente tem atitudes, ideias e comportamentos que eu chamaria de totalmente feminista, enquanto outros que descrevem a si mesmos como tal não se comportam como se fossem (TUCKER 1994 apud TRIZOLI, 2008, p, 32).

A relação entre arte e feminismo desencadeia a possibilidade de se refletir sobre aspectos sociais e morais vigentes sob o prisma do estético e do inusitado. Abre-se espaço para técnicas, expectativas e hábitos do universo privado e da subjetividade feminina.

Adriana Varejão é uma artista plástica contemporânea que vem ganhando cada vez mais destaque no espaço nacional e internacional. Sua obra reproduz elementos históricos e culturais, com temas ligados à colonização, ao barroco e à azulejaria. Investiga, também, a utilização do corpo humano, da visceralidade e da representação da carne como elemento estético. Apesar de sua obra remeter ao barroco, adquire forte contemporaneidade em decorrência do acúmulo excessivo de materiais, camadas de tinta e informações. O símbolo utilizado na obra de Varejão, por um lado, escandaliza os espectadores, mas, ao mesmo tempo, é responsável pela conquista de admiração e respeito cada vez maiores nos cenários internacionais da arte. Em sua obra, toma impulso com a pintura figurativa e gestual dos anos 1980, na qual lhe interessa a permanência das marcas do processo. A pintura constitui 
o campo maior de sua produção, incorporando elementos de outras linguagens, como a escultura.

De acordo com Fátima Cerqueira (2010), a obra de Adriana Varejão relaciona-se ao modo imbricado com que a artista transita entre a persuasão, como estratégia, que traz a ideia do barroco à atualidade, não para ser reapresentado, mas como referencial do patrimônio artístico, estético e cultural do Brasil. Está-se em meio a representações variadas entre a figura humana, o autorretrato, a carne sem corpo ou vestígios da passagem de um corpo não identificado. A artista fundamenta a construção do espaço pictórico na paródia, na narrativa fragmentada, ou mesmo em sua ausência, tecendo em seu lugar estratégias que ampliam o espaço pictórico em direção ao espaço físico em que se encontra o espectador.

Figura 1 - Figura de Convite III

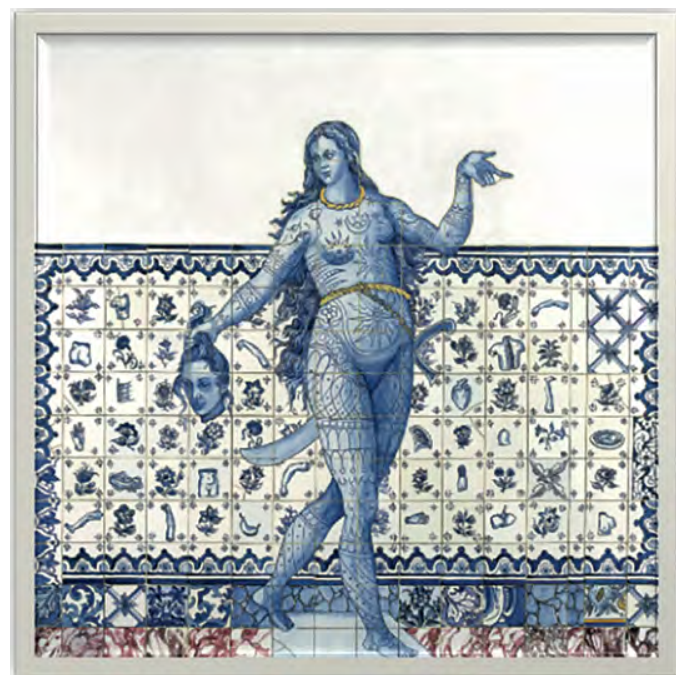

Fonte: Varejão (2005a).
Ao pintar as obras intituladas de Figura de Convite I (1997), Figura de Convite II (1998) e Figura de Convite III (2005), integrantes da série Proposta para Catequese (1993 - 1998), Adriana Varejão faz um jogo de substituições, misturando referências da azulejaria colonial portuguesa a gravuras de Theodor de Bry. Em catálogos de exposições e entrevistas, faz citação a algumas referências que envolvem seu processo de criação, em uma remontagem e uma recombinação de imagens capturadas, relacionando o enunciado crítico às questões próprias à arte contemporânea, entre as quais estão a paródia, a alegoria, o corpo, o canibalismo.

A Figura 1, intitulada Figura de Convite III, promove um diálogo intertextual com gravura de Theodor Dietrich de Bry, um dos mais importantes gravadores do século XVI. O corpo tatuado da figura feminina de Varejão foi baseado em gravura de De Bry publicada em América - Parte I. Esta gravura apresenta uma guerreira, com o corpo inteiramente tatuado, à exceção de rosto, pés e mãos. A guerreira representa um antigo povo celta que habitou a Bretanha. Mulheres celtas viveram por volta de 1.500 anos a.C., inicialmente, às margens do Rio Danúbio, na Alemanha, e depois se distribuíram pelo norte da Europa e para a Península Ibérica.

As mulheres de origem celta eram criadas tão livremente como os homens, a elas era dado o direito de escolherem seus parceiros, e nunca poderiam ser for- 
çadas a uma relação que não quisessem. Eram temidas por seus oponentes, pois elas eram treinadas para o manejo das armas, mas também amavam seus filhos com muita paixão e, para defendê-los, golpeavam e matavam selvagemente seus inimigos.

A sociedade celta sempre reservou à mulher um lugar de honra, e, nos melhores momentos irlandeses - épicos ou mitológicos -, em que o paganismo se manteve mais forte, ela aparece como poetisa encarregada de profecias e mágicas. Era livre, dona de seu destino. Mas, com a romanização e a cristianização, foi transformada em bruxa, sendo-lhe imputados todos os aspectos inferiores da magia.

A artista se vale da apropriação da imagem não como uma cópia ou uma réplica de um estilo qualquer, pressupondo, ingenuamente, que possa produzir algo idêntico ao original, possível de ser transplantado de um meio a outro, entre tempos diversos. A apropriação das imagens da azulejaria e da gravura por Varejão ocorre por intermédio da projeção de imagens sobre a tela de pintura, quando passa a (re)configurar um diferente sentido. Embora a gravura de de Bry apresente uma guerreira celta, Adriana Varejão faz um recorte e promove uma releitura dessa criação artística. Conforme aponta Lilia Moritz Schwarcz (2014), a artista parte do que tem: espalha, remonta e cria, tendo bases narrativas que, pacientemente, coleta, relê, refaz. Abre uma caixa den- tro de outra e faz de sua obra um mar de histórias.

De acordo com Frenkel e Monteiro (2013), verifica-se na obra de Varejão que o objeto artístico se desprende, assim, das cronologias lineares e dos mapas reconhecíveis, para restar como um corpo aberto, como um espaço em que a memória se atualiza de forma dinâmica, imperfeita e estilhaçada que se abre à multiplicidade, como uma "câmara de ecos", como o espaço onde escutamos ressonâncias sem nos ater a uma sequência ou a qualquer noção de causalidade, onde o eco precede, muitas vezes, a voz.

O corpo feminino, na obra Figura de Convite III, apresenta desenhos com traços simétricos e espirais com linhas pretas bem marcadas. Os espirais que cobrem a perna da mulher representam o movimento da energia, as fases cíclicas da vida, símbolos rituais que se tornam um fator de ação social aliados às ações culturais, que possuem caráter de sistemas semânticos, ao projetar significados. Nesse caso, as espirais desenhadas no corpo convergem para imagem de mulher detentora de força e persistência, que na maioria das vezes é concernente somente ao homem viril. Saffioti discute essa premissa ao questionar:

O mero fato de a mulher deter, em geral, menos força física que o homem seria suficiente para "decretar" sua inferioridade? (1987, p. 13).

Para Saffioti: 
Os fatos históricos indicam que não. Somente para ilustrar esta questão, evoca-se o fato de que em todos os momentos de engajamento de um povo em uma guerra, via de regra, os homens são destinados ao combate, enquanto as mulheres assumem as funções antes desempenhadas pelos elementos masculinos. Por que são elas capazes de trabalhar em qualquer atividade para substituir os homens-guerreiros, devendo retornar ao cuidado do lar, uma vez cessadas as ações bélicas? (1987, p. 12).

\section{Para Le Goff}

O corpo tem uma história. A concepção do corpo, seu lugar na sociedade, sua presença no imaginário e na realidade, na vida cotidiana e nos momentos excepcionais sofreram modificações em todas as sociedades históricas (2007, p. 10).

Nos tempos antigos, o desenho no corpo era um significante importante de posição social, conhecimento, habilidade e qualificação para se casar. Observa-se que as tatuagens, que marcam o corpo da guerreira, não são de origem celta, mas em estilo maori, intitulada Ta Moko. Assim, a tatuagem reflete a whakapa$p a$ (ancestralidade) do indivíduo e sua história pessoal; diferentemente das demais tatoos, as tatuagens maori são feitas com base na história pessoal de quem é tatuado. Elas, nas mulheres, representam a passagem para a vida adulta, a metamorfose ocorrida entre $o$ ser menina e o ser mulher. Os maoris são o povo nativo originário da Nova Zelândia; para essa população, as tatuagens possuem um significado muito além da estética. Através do corpo, o ser humano se apresenta, estabelece contato com o mundo, reconhece, identifica e diferen- cia-se. A tatuagem pode ser vista como uma forma de identificação e também de diferenciação. Cada desenho pode ter ou não um significado específico.

Segundo Souza (2001 apud ALVARENGA, 2005), a tatuagem fez parte da evolução do homem, nasceu da necessidade de domar a natureza e da consciência que o corpo era insuficiente. As marcas no corpo vieram primeiramente para marcar fatos biológicos, como nascimento, reprodução e morte; depois, fatos da vida social, papéis exercidos, como por exemplo : guerreiros, reis ou prisioneiros. Existem evidências da prática da tatuagem em 5300 a.C., no homem de gelo, com linhas, cruzes e faixas tatuadas.

A tatuagem, dessa maneira, passa a ter um valor de identidade expresso no próprio "âmago da carne". Pode ser uma maneira de escrever, metaforicamente, na carne, momentos importantes da existência. É uma memória de um acontecimento forte, passagem pela qual o sujeito deseja conservar uma lembrança. As marcas corporais também implicam uma vontade de atrair o olhar, de ser visto e reconhecido.

A marca é um limite simbólico desenhado sobre a pele, fixa uma batente na busca de significado e de identidade, é uma espécie de assinatura de si pela qual o indivíduo se afirma em uma identidade escolhida (LE BRETON, 2003, p. 40).

As tatuagens maori, em corpos femininos, restringiam-se a lábios e queixo, não ao corpo todo, como visto em Figura de Convite III. Embora no rosto da figura retratada não haja registro de prestígio 
e poder, no restante do corpo, elas apresentam total empoderamento, já que os símbolos usados eram comuns apenas em corpos viris dos guerreiros maoris. A representação da mulher, nessa obra, não corresponde às perspectivas masculinas, brancas e ocidentais e produz, consequentemente, efeitos sobre os modos de pensar, ver e viver as noções de gênero, raça e sexualidade, rompendo com o "poder do macho", conforme Saffioti (1987). Há, também, um embate com aquilo que a pesquisadora Luciana Loponte (2008) chama de uma "pedagogia visual do feminino", que, por sua vez, produz uma ideia igualmente universalizante $\mathrm{e}$ essencialista sobre o ser mulher:

Podemos então falar da produção de uma "pedagogia do feminino", uma pedagogia visual que toma como "verdade universal" uma forma muito particular de olhar. Uma pedagogia que, de tão incorporada a nossa própria subjetividade, quase nos impede de ver a multiplicidade de femininos possíveis, distantes das representações mais comuns de passividade, submissão e delicadeza (LOPONTE, 2008, p. 155).

Jules Suzdaltsev (2017) assevera que, ao tatuar a pele, as pessoas afirmam suas identidades; a isso ele denomina de "antropologia da autoestima e identidade". O corpo é uma forma de comunicação, assim, ao analisarmos a marca do Sol, que aparece em mais de um momento na obra Figura de Convite III, observamos que ela carrega o simbolismo da esperança em uma demonstração de superação de dificuldades. Além disso, liga-se à representação do conhecimento e do poder. A mulher criada por Varejão é dotada de características do empoderar-se, ou seja, afasta-se do modelo que a sociedade espera, aceitando aquilo que é imposto; libera-se, principalmente, das amarras do perfeccionismo, fazendo com que o conhecimento se sobreponha à estética corporal.

Em volta do corpo, na altura do abdômen, há uma corda e nela uma corrente. A corda é um símbolo ancestral, com significados religiosos, místicos e até filosóficos. Em seu aspecto positivo, é um símbolo de união; enquanto que, em seu aspecto negativo, representa a escravidão, posto que tanto une como isola. Dessa forma, a obra remete à escravidão que, ainda, existe no tocante a mulheres em várias situações; há casos em que são submetidas a ter filhos que não desejam, muitas não têm dinheiro próprio, não têm acesso a educação ou trabalho. A corrente complementa essa ideia, pois pode significar, em uma perspectiva mais sociopsicológica, uma necessidade de adaptação a um grupo, ainda que seja uma integração imposta, ou seja, a busca por ter voz em meio à opressão.

A mão esquerda da mulher leva uma cabeça decapitada, suspensa pelos cabelos, que é um autorretrato de Varejão; dessa forma notamos que a artista trata seu próprio corpo como objeto de representação, assumindo-se como sujeito de criação. De acordo com Paulo Herkenhoff (1996), a pintura retalhada de Varejão expande-se por pulsações e, como um organismo aberto, não encerra uma totalidade de sentido, antes abre 
caminho para que a vida se atualize no contato com o espectador.

A cabeça possui, para muitos povos, um grande valor, estando ligada ao princípio ativo e ao fato de governar, ordenar e instruir. De acordo com Platão, é comparável, devido à sua forma circular, a um universo e ao microcosmo (1953 apud CHEVALIER; GHEERBRANT, 1998, p. 152).

O corte das cabeças está relacionado às concepções sobre a alma. Para os celtas, os seres humanos teriam duas almas: uma que deixa o corpo após a morte e outra, como princípio de vida imortal, que se perpetua de geração a geração até o fim dos tempos (STERCKX, 2009 apud ZIERER, 2011). Somente eram guardadas como troféus as cabeças de heróis prestigiosos. Já que não se sabia qual era o princípio gerador da vida, os celtas acreditavam que ele estivesse ligado ao esperma, à capacidade sexual masculina. Para Zierer (2011), daí vem a crença de que o transmissor da continuidade genética era somente o homem. Assim, só eram cortadas as cabeças do inimigo masculino, estando reservado às mulheres o corte dos seios, para que a sua geração não tivesse continuidade através do líquido gerador (associado ao esperma) ou alimentador (o seio).

Varejão subverte a lógica ao colocar a imagem de uma cabeça feminina decapitada. Há um esforço em representar a relação mulher-arte-poder, assim, de alguma forma, encadeiam-se discursos sobre poder, relativos às diferenças de gênero (NOCHLIN, 1971 apud LOPONTE, 2008, p. 155). Existe uma preocupação, portanto, em expor e conectar histórias marginais, histórias contra a corrente, contadas às margens, neste caso, história subalterna: a das mulheres, que por meio dessa representação ganha uma dimensão política.

\section{No fim do Caminho, (in)conclusões}

A mulher busca os seus idiomas próprios, nos espaços recém-abertos para ela (FROTA, 2003 apud ALMEIDA, 2010).

As últimas décadas do século XXI estão marcadas pela inclusão das mulheres no meio artístico e em todas as possíveis formas de expressão artística. Assuntos que antes eram exclusivamente masculinos são abordados abertamente por qualquer pessoa. Hoje, opta-se por falar ou não sobre os assuntos que pertencem ao mundo das mulheres. As artistas têm a liberdade de expressão, principalmente a partir dos anos 1990, e surpreendem ao romperem com padrões chamados "femininos", reciclando e reinventando acervos materiais e simbólicos constituintes do universo feminino há muito tempo. Subvertem, pois, o discurso dominante e oficial sobre arte, a narrativa masculina considerada como narrativa universal, uma verdade inquestionável que vale para todos e todas.

Há muitas formas de enunciar o feminino pela arte, algumas artistas colaboram rompendo os modos de ver e 
pensar a arte, produzindo outros significados para o próprio feminino. Abrem possibilidades para repensar as imagens de mulher na arte além dos pares passividade/atividade e feminilidade/masculinidade como categorias imutáveis. São, de alguma maneira, formas de construir estratégias de resistência às relações de poder que envolvem gênero e arte.

Na produção artística de Adriana Varejão Figura de Convite III, observamos um posicionamento político esteticamente transgressor, funcionando como espaços de resistência política e como oposição ao discurso sobre a "natural" domesticidade feminina, que contesta discursos ideológicos vigentes por meio da própria materialidade das obras. Varejão subverte, desloca e desconstrói as imagens de feminilidade e transforma-as em uma crítica política. De acordo com Simioni et al., a condição de duplamente dominadas permitiu às artistas transitar da "marginalidade como externalidade do poder à margem como questionamento do simbolismo do poder" (2013, p. 59). Ainda segundo as autoras:

[...] é preciso notar que, ainda que as obras sejam contundentes, isso não significa que as artistas se identifiquem como "feministas", muitas delas se recusavam, e ainda hoje se recusam, a se verem catalogadas como feministas. Com isso, é preciso destacar a diferença reconhecida desde as práticas artísticas e políticas entre um desejo de militância "geral" e uma militância feminista tout court. Muitas das obras e artistas aqui analisadas possuem obras que assinalam poéticas feministas, sem que suas autoras se vejam atreladas a algum tipo de militância externa ao próprio campo artístico (SIMIONI et al., 2013, p. 8).
Frenkel e Monteiro (2013) asseveram que o corpo na obra de Adriana Varejão se exibe como matéria que experimenta, dissolve e reorganiza o tempo e a memória, reunindo seus vestígios e guardando-os para as infinitas atualizações do passado no presente e no futuro. Mais do que discursos que apenas refletem ou nomeiam uma determinada realidade, as imagens criadas pelo artista produzem verdades sobre sujeitos, produzem práticas sociais. Há vários discursos que representam, nas artes visuais, práticas de poder articuladas à produção de verdades sobre gênero e sexualidade. No entanto, se as relações de poder pendem em determinados períodos históricos e culturais para um determinado modo de ver, isso não quer dizer que assim o sejam indefinidamente.

Segundo Barreto (2013), a arte tem sido a maneira pela qual algumas mulheres têm articulado seus discursos de resistência. As subculturas identitárias representadas pela beleza alternativa mostrada, por exemplo, na arte feminista têm dado a esses corpos a possibilidade de se tornarem mais visíveis através da internet. No entanto, há de se considerar que não há um discurso único sobre a arte, imune a resistências e deslocamentos, mas discursos que refletem ou nomeiam uma determinada realidade. 


\section{The female body in the work of Adriana Varejão: transgression and rupture}

\begin{abstract}
His article analyzes the representation of the female body in the work of the plastic artist Adriana Varejão, recognizing art as a vehicle of signification and visual communication. The body is a form of identification of the feminine and the masculine, but is especially regarded as a stigma of the representation of masculine power. Throughout history, the division between the public, with regard to the masculine roles, and the private, with respect to the feminine roles, is evident. It is for the scope of the artistic representation that we will return our look, that is, analysis of how the aesthetic look of the author in the capture of the dominant conception in the poetics of the feminine body takes place. We adopt the hermeneutical method of analysis, modern hermeneutics encompasses not only written texts but also everything that exists in the interpretative process. This includes verbal and non-verbal forms of communication as well as aspects that affect communication. To interpret means to attribute the content, meaning and scope of a normative text, aiming at its application to a concrete case.
\end{abstract}

Keywords: Adriana Varejão. Art. Body. Woman.

\section{Referências}

ALMEIDA, Flávia Leme de. Mulheres recipientes: recortes poéticos do universo feminino nas artes visuais. São Paulo: Cultura Acadêmica, 2010. (Coleção PROPG Digital - UNESP).

AUMONT, J. A Imagem. Campinas: Papirus, 1993.

BARRETO, Nayara Matos. O corpo feminino nas artes visuais: nudez, sexualidade e empoderamento. 2013. Disponível em <https:// www.maxwell.vrac.puc-rio.br/23052/23052. PDF>. Acesso em: 19 jun. 2017.

BEAUVOIR, Simone de. Segundo Sexo: a experiência vivida, v. 2, Difusão Europeia do Livro, 1970.

BOURDIEU, Pierre. Conferência do Prêmio Goffman: a dominação masculina revisitada. In: LINS, Daniel (Org.). A dominação masculina revisitada. Campinas, SP: Papirus, 1999. p. 11-28.

CERQUEIRA, Fátima Simões. Monocromia, Antropomorfia e Persuasão. In: ENCONTRO DAASSOCIAÇÃO NACIONAL DE PESQUISADORES EM ARTES PLÁSTICAS, 19., 2010, Cachoeira, BH. Anais... Cachoeira, BH. 2010. Disponível em: <http://www.anpap.org. br/anais/2010/pdf/chtca/fatima_nader_simoes_cerqueira.pdf $>$. Acesso em: 08 jun. 2017.

CHEVALIER, Jean; GHEERBRANT, Alain. Dicionário de Símbolos. Rio de Janeiro: José Olympio, 1998.

FRENKEL, Eleonora; MONTEIRO, Rebecca. Clarice Lispector e Adriana Varejão: o corpo aberto da escrita e da arte. Revista Aletria, Belo Horizonte, n. 3, v. 23, p. 73-83, set./ dez. 2013.

KATZ, H.; GREINER, C. A natureza cultural do corpo. In: PEREIRA, Silvia Soter Roberto (Org.) Lições de Dança 3. Rio de Janeiro: UniverCidade, 1998. p. 77-102. 
GROSZ, Elisabeth. Corpos reconfigurados. Cadernos Pagu, Unicamp, Campinas, v. 14, p. 45-86, 2000.

JOLY, Martine. Introdução à análise de imagem. Campinas, SP: Papirus, 1996. (Coleção Ofício Arte e Forma).

HERKENHOFF, Paulo. Pintura/Sutura. São Paulo: Galeria Camargo Vilaça, 1996. Disponível em: <http://www.adrianavarejao. net/pt-br/pinturasutura $>$. Acesso em: 20 mar. 2017.

LE BRETON, David. Adeus ao corpo: antropologia e sociedade. Campinas: Papirus, 2003.

LE GOFF, Jacques. As raízes medievais da Europa. Petrópolis, RJ: Vozes, 2007. p. 71-86.

LOPONTE, Luciana Gruppelli. As pedagogias visuais do feminino: arte, imagens e docência. Currículo sem Fronteiras, 2008, v. 8, n. 2, p. 148-164, jul./dez. 2008.

MATOS, M. I. S. de. Gênero e história: percursos e possibilidades. In: SCHPUN, M. R. (Org.). Gênero sem fronteiras: oito olhares sobre mulheres e relações de gênero. Florianópolis: Editora Mulheres, 1997, p. 80.

PERROT, Michelle. Minha história das mulheres. São Paulo: Contexto, 2007.

NOVAES, J. V. O intolerável peso da feiúra sobre as mulheres e seus corpos. Rio de Janeiro: PUC-Rio, 2006.

SAFFIOTI, Heleieth I. B. O Poder do Macho. São Paulo: Editora Moderna, 1987. p. 12-16.

SIMIONI, Ana Paula Cavalcanti et al. Mulheres criadoras na América Latina: o desafio de sintetizar sem singularizar. 2013. Disponível em: <http:/cral.in2p3.fr/artelogie/ spip.php?page=imprimir_articulo\&id_article=287 . . Acesso em: 02 jun. 2017.

SCHWARCZ, Lilia Moritz; VAREJÃO, Adriana. Pérola imperfeita: a história e as histórias na obra de Adriana Varejão. São Paulo: Cobogó; Companhia das Letras, 2014.
THOMPSON, John B. Ideologia e cultura moderna: teoria social e crítica na era dos meios de comunicação de massa. Petrópolis: Vozes, 1995.

TRIZOLI, Talita. O Feminismo e a Arte Contemporânea - considerações. 2008. Disponível em: <http://feminismo.org.br/web/ wp-content/uploads/2014/09/Feminismo-e-arte-contempor\%C3\%A2nea_Talita-Trizoli. pdf>. Acesso em: 20 jun. 2017.

SUZDALTSEV, Jules. Tatuagem e Psicologia. Entrevista. 2017. Disponível em: <https:// memoriestattoo.wordpress.com/2017/01/24/ 7-motivacoes-que-fazem-voce-se-tatuar-segundo-psicologo-tatuagem-e-psicologia/> Acesso em: 21 maio 2017.

VAREJÃO, Adriana. Figura de Convite III. 2005a. Disponível em: <http://www.adrianavarejao.net>. Acesso em: 11 abr. 2017

. Bate-papo com Adriana Varejão. 2005b. Disponível em: <http://tc.batepapo. uol.com.br/convidados/.../arquivo/arte/>. Acesso em: 06 jun. 2017.

XAVIER, E. Que corpo é esse? O corpo no imaginário feminino. Florianópolis: Editora Mulheres, 2007.

ZIERER, Adriana. Simbologia da Cabeça cortada entre os celtas e algumas analogias com o mito da Górgona. 2011. Disponível em: <https://digitalis-dsp.uc.pt/bitstream/10316.2/33066/1/Phoinix17-1_artigo8. pdf?ln=pt-pt>. Acesso em: 07 jun. 2017. 